\title{
Integrated Sensor for Estimating in situ Soil Water Content in Vertical Profile
}

\author{
Iftikhar Ahmed Saeed ${ }^{1,2, \uparrow}$, Wang Minjuan ${ }^{1,2, \uparrow}$, Ji Qiang $^{3}$, Shi Qinglan ${ }^{1,2}$, Zheng Li Hua ${ }^{1}$, \\ Liu Xinliang $^{4} \&$ Gao Wanlin ${ }^{1,2}$ \\ ${ }^{1}$ College of Information and Electrical Engineering, China Agricultural University, Beijing, China \\ ${ }^{2}$ Key Laboratory of Agricultural Informationization Standardization, Ministry of Agriculture, Beijing, China \\ ${ }^{3}$ Space Star Technology Co., Ltd., Beijing, China \\ ${ }^{4}$ Beijing Technology and Business University, Beijing, China \\ Correspondence: Gao Wanlin, College of Information and Electrical Engineering, China Agriculture University, \\ Beijing 100083, China, E-mail: gaowlin@cau.edu.cn \\ Shi Qinglan, College of Information and Electrical Engineering, China Agriculture University, Beijing 100083, \\ China.E-mail: shiql@cau.edu.cn \\ Liu Xinliang, Beijing Technology and Business University, Beijing, China. E-mail: 2690684625@qq.com
}

Received: June 12, $2018 \quad$ Accepted: July 22, $2018 \quad$ Online Published: September 15, 2018

doi:10.5539/jas.v10n10p53 URL: https://doi.org/10.5539/jas.v10n10p53

${ }^{\dagger}$ These authors contributed equally to this work.

\begin{abstract}
Many agricultural and hydrological processes require the detailed knowledge of soil water content (SWC) in the vertical profile. Quantifying real-time and in situ SWC is difficult due to time, cost, toil, and technical issues. This paper describes the development of a multi-depth SWC monitoring sensor which can estimate the SWC from 4 vertical depths simultaneously. The probe is a type of electromagnetic (EM) sensor that indirectly measures the SWC on the basis of dielectric theory. The sensor was calibrated with soil samples of three distinct topographical locations. The calibration models were established by fitting linear order equations. The performance of the sensor was evaluated in situ field conditions. A multi-depth SWC curve was investigated to examine the impact of continuous estimations of SWC at specified depths on the sensor performance. The sensor was integrated with vertical interpolation technique to improve the measurement accuracy. The results indicated the optimal range of the SWC measurements, and the estimation error was less than 5\%, except irrigation cycles. The linear fit coefficient of determination $\left(\mathrm{R}^{2}\right)$ ranged from 0.957 to 0.993 and root mean square error (RMSE) was ranging from 1.565 to 4.456 . The results showed that the sensor performed consistently better for at least 4 months within acceptable soil conditions. The sensor will be advantageous for continuous estimations of SWC, and managing the irrigation practices.
\end{abstract}

Keywords: dielectric sensor; multi-depth, soil water content, vertical distribution, interpolation

\section{Introduction}

The vertical distribution of SWC plays a significant role in various agricultural and hydrological processes (Pal, Maity, \& Dey, 2016). The vertical profile of SWC is driven by various factors including; time, space, soil structure, type, dry and wet conditions, water holding capacity, meteorological conditions, vegetation, topography, and cropping cycle as well (Li, Shao, Jia, \& Wei, 2016; Ojha, Morbidelli, Saltalippi, Flammini, \& Govindaraju, 2014; Stewart, 1996; Western, Grayson, \& Blöschl, 2002). The continuous monitoring of SWC at a classical point is very important because it varies significantly with depth. The SWCs at shallows depths $(0-0.28$ $\mathrm{m})$ are more dynamic than lower depths. Therefore, the precise estimation of SWC in the vertical profile becomes challenging (Holmes et al., 2012; Morbidelli, Corradini, Saltalippi, \& Brocca, 2012; Ojha et al., 2014; Wang et al., 2015; Wilson et al., 2003).

In recent years, a large number of automatic techniques for scaling the SWC on point and large scale have been developed. The performance of SWC monitoring devices has been tested for a wide variety of soil types in 
laboratory and field conditions (Evett, Heng, Moutonnet, \& Nguyen, 2008; Luhr \& Kleisinger, 1998; Romano, 2014; Walker, Willgoose, \& Kalma, 2004). The estimation of the dielectric constant of a soil has emerged as an elegant method for measuring the SWC. EM methods, in general, either time domain reflectometry (TDR) for local estimations, ground penetrating radar (GPR), capacitance probes, and Frequency domain reflectometry (FDR) all measure the SWC by estimating the dielectric constant (Dean, Bell, \& Baty, 1987; Topp, 2003; Topp, Davis, \& Annan, 1980). The other devices such as impedance probes, tensiometers (Chow et al., 2009; Ling, 2004), resistance blocks (Hignett \& Evett, 2008; Ling, 2004), heat dissipation type sensor (Hignett \& Evett, 2008; Ling, 2004), and neutron sensors could be used for measuring the SWC (Evett et al., 2008). However, the above mention techniques have some problems such as the GPR active microwave and passive microwave operate on scattered EM waves penetrating into the soil or being reflected from it. The vegetation and surface coarseness limit the sensitivity and only can scan the upper depths $(\sim 10 \mathrm{~cm})$ (Entekhabi et al., 2010; Li, Toll, Zhan, \& Cosgrove, 2012). TDR is a widely used technique to monitor SWC at point scale however it destroys the soil structure and also impacted by material heterogeneity and electrical conductivity at different soil depths. In addition, it is an expensive approach (Baldwin, Manfreda, Keller, \& Smithwick, 2017; Greco \& Guida, 2008; Stangl, Buchan, \& Loiskandl, 2009). The other concerns related to EM based technology include; over-under estimations of SWC with factory specifications, impacted by soil salinity and electric conductivity, and small air gaps could impact the measurements significantly. The poor performance of the probes at $0.35-0.50 \mathrm{~m}$ soil depths has been reported, and at deeper soil depths $(0.60-0.80 \mathrm{~m})$ monitoring ability of the dielectric sensors have been questioned (Chow et al., 2009; Kumar et al., 2009; Leib, Jabro, \& Matthews, 2003; Mittelbach, Lehner, \& Seneviratne, 2012; Parsons \& Bandaranayake, 2009; Romano, 2014; Topp, 2003). In recent decades, various statistical approaches were applied to predict the temporal distribution of SWC. The linear and cubic interpolation techniques were found to be the best for infilling randomly missing moisture values (Fernández-Gálvez, Simmonds, \& Barahona, 2006; İmamoğlu \& Sertel, 2016; Kornelsen \& Coulibaly, 2012).

This study describes the development of a high-resolution integrated sensor for open and controlled environments, which can continuously measure the SWC from 4 vertical depths $(0.20$ to $0.80 \mathrm{~m})$ simultaneously in different environmental and terrain conditions. At the same time, the sensor can transfer the measured data to the user terminal and data bank. The main objectives of the study were to: (i) design and develop a multi-depth SWC monitoring sensor with a minimum damage to the original soil structure; (ii) integrate with the automatic irrigation systems; (iii) calibrate the sensor with different soil types; (iv) analyze the effect of continuous estimations of SWC at specified depths within the soil horizon on the sensor performance; and, (v) evaluate the performance of the sensor in situ.

\section{Materials and Methods}

\subsection{Sensor Development and Measurement Principle}

A multi-depth (4 depths) SWC monitoring probe was developed in this study. The developed probe is a type of EM sensor that indirectly estimates the SWC on the basis of the dielectric property of soil (Topp et al., 1980). The capacitance of the probe can be measured by two methods. The traditional method uses the frequency measurement technique. The frequency changes with the capacitance, which is influenced by the dielectric constant of the medium (Dean et al., 1987). The dielectric constant of various media also varies such as water is 80, soil (2.4-3.5), and soil minerals dielectric constant ranged from 2.7 to 5.0. Therefore, the change in SWC will impact the soil dielectric constant, subsequently. The second method measures the electrical impedance of the soil at a definite excitation frequency. The sensor functioned at a $100 \mathrm{MHz}$ frequency (Dean, 1994; Kargas \& Kerkides, 2009; Kelleners et al., 2004; Stacheder, Koeniger, \& Schuhmann, 2009). Figure 1 describes the monitoring principle circuit for SWC monitoring. The sensor outputs a DC voltage that is converted into SWC by the calibration equations already embedded into the sensor. The probe impedance in the medium is determined by the following Equation (1):

$$
Z_{\mathrm{i}}=-\mathrm{j} \frac{\mathrm{Z}_{\mathrm{C}}}{\sqrt{\varepsilon}} \operatorname{ctg} \frac{2 \pi \sqrt{\varepsilon}}{\lambda_{0}} 1
$$

Where, $Z_{C}$ the impedance of the probe in the air, $L$ represents the probe length, $\lambda_{0}$ wavelength of the sine wave signal in the air; $\varepsilon$ represents the dielectric constant of the soil around the probe. In terms of angular frequency of electromagnetic waves $\omega$, then Equation (1) can be simplified as Equation (2):

$$
Z_{\mathrm{i}}=-\mathrm{j} \frac{Z_{\mathrm{C}}}{\sqrt{\varepsilon}} \operatorname{ctg} \frac{2 \pi \sqrt{\varepsilon}}{\lambda_{0}} 1=\frac{Z_{\mathrm{C}}}{\mathrm{j} \omega \sqrt{\varepsilon}} \operatorname{ctg} \frac{2 \pi \sqrt{\varepsilon}}{\lambda_{0}}
$$

The resistance of the sensing probe is related to the SWC when the probe is placed in air. It can be expressed as follows: 


$$
\begin{gathered}
\mathrm{Y}_{\mathrm{L}}=\mathrm{Z}_{\mathrm{L}}^{-1}=\left[j \omega \mathrm{C}_{1}+\frac{1}{j \omega \mathrm{L}+\frac{1}{j \omega\left(\mathrm{C}_{2}+\mathrm{C}_{\mathrm{X}}\right)}}\right]^{-1}=(j \omega)^{-1}\left[\frac{\mathrm{C}_{1}+\mathrm{C}_{2}+\mathrm{C}_{\mathrm{x}}-\omega^{2} \mathrm{LC}_{1}\left(\mathrm{C}_{2}+\mathrm{C}_{\mathrm{x}}\right)}{1-\omega^{2} \mathrm{~L}\left(\mathrm{C}_{2}+\mathrm{C}_{\mathrm{x}}\right)}\right]^{-1} \\
\mathrm{U}_{1}=\frac{\mathrm{Z}_{\mathrm{L}}}{\mathrm{R}+\mathrm{Z}_{\mathrm{L}}} \mathrm{u}_{\mathrm{i}}=\frac{\frac{1-\omega^{2} \mathrm{~L}\left(\mathrm{C}_{2}+\mathrm{C}_{\mathrm{x}}\right)}{\mathrm{C}_{1}+\mathrm{C}_{2}+\mathrm{C}_{\mathrm{X}}-\omega^{2} \mathrm{C}_{1}\left(\mathrm{C}_{2}+\mathrm{C}_{\mathrm{x}}\right)}}{\mathrm{R}+\frac{1-\omega^{2} \mathrm{~L}\left(\mathrm{C}_{2}+\mathrm{C}_{\mathrm{x}}\right)}{\mathrm{C}_{1}+\mathrm{C}_{2}+\mathrm{C}_{\mathrm{x}}-\omega^{2} \mathrm{~L} \mathrm{C}_{1}\left(\mathrm{C}_{2}+\mathrm{C}_{\mathrm{x}}\right)}} \mathrm{u}_{\mathrm{i}}=\frac{1-\omega^{2} \mathrm{~L}\left(\mathrm{C}_{2}+\mathrm{C}_{\mathrm{x}}\right)}{\mathrm{R}\left[\mathrm{C}_{1}+\mathrm{C}_{2}+\mathrm{C}_{\mathrm{x}}-\omega^{2} \mathrm{LC}_{1}\left(\mathrm{C}_{2}+\mathrm{C}_{\mathrm{x}}\right)\right]+\left[1-\omega^{2} \mathrm{~L}\left(\mathrm{C}_{2}+\mathrm{C}_{\mathrm{x}}\right)\right]} \mathrm{u}_{\mathrm{i}} \\
\mathrm{U}_{2}=\frac{\frac{1}{j \omega\left(\mathrm{C}_{2}+\mathrm{C}_{\mathrm{X}}\right)}}{\mathrm{j} \omega \mathrm{L}+\frac{1}{\mathrm{j} \omega\left(\mathrm{C}_{2}+\mathrm{C}_{\mathrm{x}}\right)}} \mathrm{U}_{1}
\end{gathered}
$$

Where $U_{1}, U_{2}$ are the two poles of the inductor, and $L$ is voltage. $C_{x}$ is the equivalent capacitance value of the perception rings, $\omega$ is the angular frequency of electromagnetic waves, $u_{i}$ represents high the frequency of electromagnetic wave signals $u_{i}=A \cos \omega t$. The probe capacitance will minimum when $C_{x}$ is in the air or in the dry soil, at that time $\mathrm{L}$ and $\mathrm{C}_{2}$ are the series resonance in the signal frequency $100 \mathrm{MHz}$, which is expressed as:

$$
\omega \mathrm{L} \cong \frac{1}{\omega\left(\mathrm{C}_{2}+\mathrm{C}_{\mathrm{x}}\right)}
$$

The $U_{1}=0$ when the probe is connected to the circuit, then $\left|U_{2}\right|=\frac{\frac{1}{\omega\left(C+C_{x}\right)}}{\omega L-\frac{1}{\omega\left(C+C_{x}\right)}} U_{1}$.

When $C_{x}$ increases frequency the voltage at the $U_{2}$ becomes smaller. Therefore, the voltage of $U_{2}$ and $C_{x}$ will steep. Meanwhile, $\mathrm{U}_{1}$ gradually approaches to equivalent inductance $\mathrm{C}_{1}, \mathrm{~L}, \mathrm{C}_{\mathrm{x}}$ and $\mathrm{C}_{2}$, which is based on a parallel resonant circuit $\mathrm{U}_{1}=\mathrm{u}_{0}$.

The change procedure is: The change in $U_{1}, U_{2}$, and $C_{x}$ will impact the relationship between $U_{1}-U_{2}$ and $C_{x} \cdot U_{1}$ and $\mathrm{U}_{2}$ will be added to high impedance detection circuit, and through the differential amplifier output $U_{\text {out }}=k\left(U_{1}-U_{2}\right) . U_{\text {out }}$ changes with the change of $C_{x}$ where $C_{x}$ is based on the dielectric constant of the soil which represents the SWC.

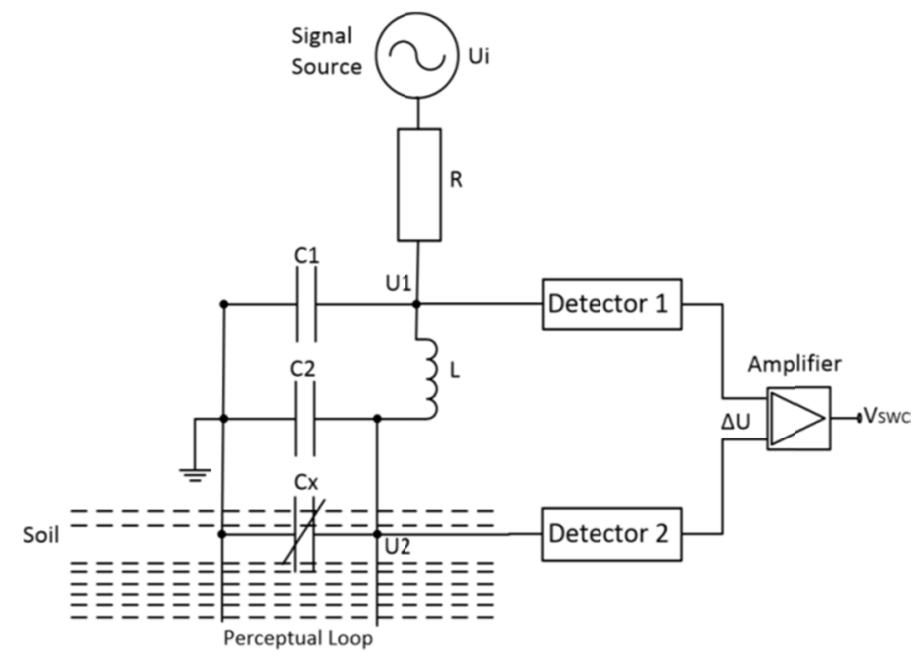

Figure 1. The equivalent circuit of SWC monitoring principle

\subsubsection{Hardware Development}

The developed probe consisted of different modules including; sensor acquisition module (SAM), detection tube, a processing module (PM), high-frequency oscillation module, wireless communication module (WCM), and power supply module (PSM). The processing module (PM) consisted of CPU (ARM7), CAN bus 2.0B communication protocol, acquisition channel of 8 bit, 12 bit and $\mathrm{A} / \mathrm{D}$ conversion and $0 \sim 5 \mathrm{~V}$ analog input voltage signal. Data acquisition control processes the collected data and prepares it to be transmitted wirelessly. Wireless communication unit was used for sending the data from the sensor to the user terminal via Wi-Fi/GPRS. The power supply unit (PSU) provides power for other modules. The input voltage of PS was $3.6 \mathrm{~V}$ with batteries. PS elevates the input voltage from $3.6 \mathrm{~V}$ to $5 \mathrm{~V}$ through a voltage pump in order to supply power for SAM. The system block diagram is shown in Figure 2. 
The probe with perception rings was housed in a polycarbonate transparent assess tube with an inside and outside diameter of $36 \mathrm{~mm}$ and $39 \mathrm{~mm}$, respectively. The probe tube encloses four identical stainless steel moisture sensing rings $\mathrm{C}_{\mathrm{x} 1} \sim \mathrm{C}_{\mathrm{x} 4}$ located along it and four temperature sensitive resistors RT1 RT. The perception rings form a capacitor that generates an EM field around the probe. The perception rings and temperature sensitive resistors can detect SWC and temperature from four vertical soil depths simultaneously. The field-specific calibration is recommended especially where the SWC magnitude is high. The probe calibration accuracy was $\pm 0.03 \mathrm{~m}^{3} \mathrm{~m}^{-3}$.

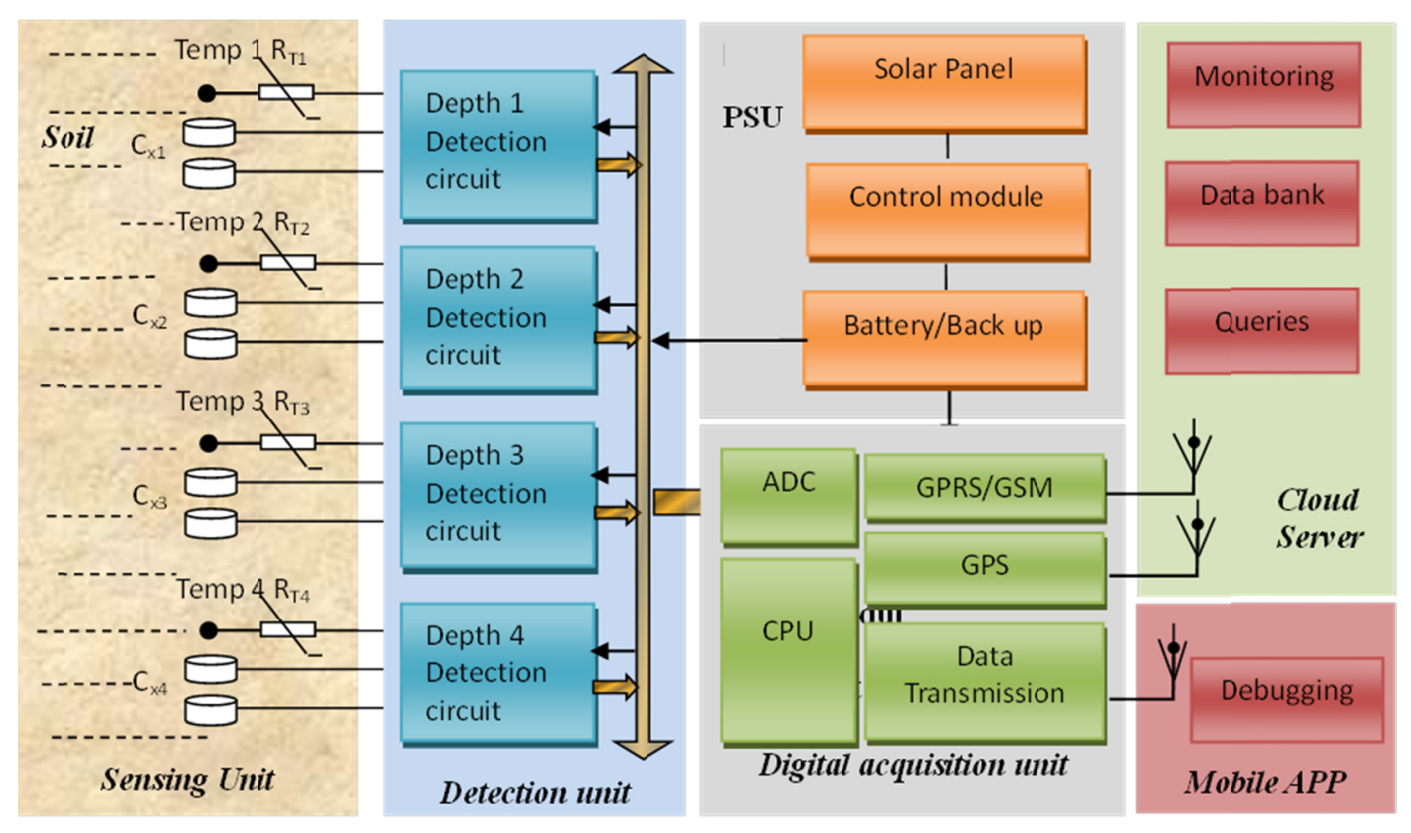

Figure 2. Block diagram of the multi-depth sensor

\subsubsection{Software Development}

In order to meet in situ requirements, a software application was developed: (1) easy to install; (2) reliable measurements of the SWC and temperature; (3) good security from being damp and (4) cost efficient. The detailed flowchart is shown in Figure 3. 


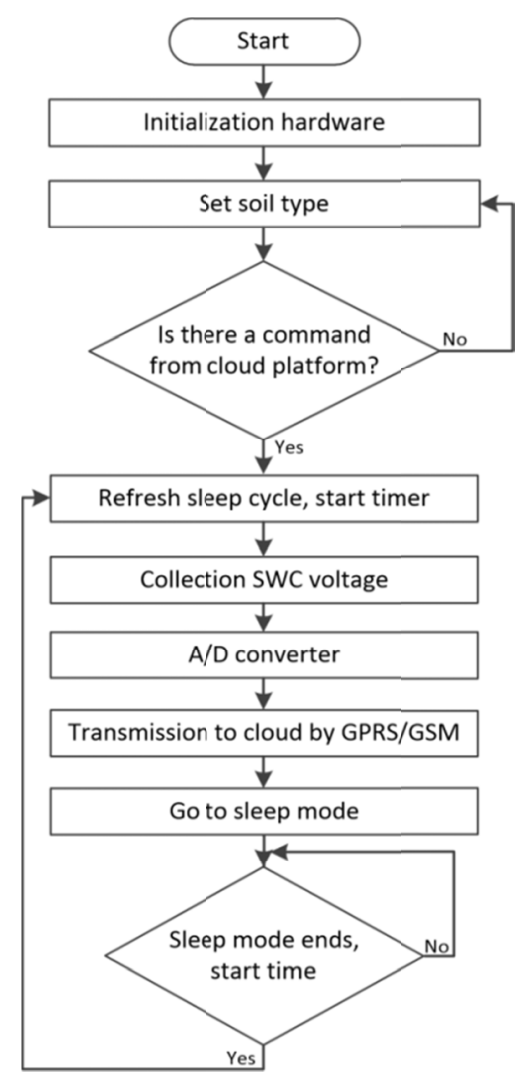

Figure 3. Flowchart of sensor software

\subsection{Sensor Calibration Experiments Design}

A systematic procedure was adopted to calibrate the sensor. The soil samples were taken from three topographical locations of China including the east campus of China Agricultural University (CAU) field, greenhouse and Kunming peach field. The east campus of CAU and greenhouse are located in Beijing $\left(39^{\circ} 90^{\prime} \mathrm{N}\right.$, $\left.116^{\circ} 39^{\prime} \mathrm{E}\right)$, whereas peach field is located in Kunming $\left(25^{\circ} 3^{\prime} \mathrm{N}, 102^{\circ} 71^{\prime} \mathrm{E}\right)$. The collected soil samples composition was as; Beijing 68\% sand, $25 \%$ loam and 7\% clay whereas Kunming field soil were 30\% sand, 15\% loam, and 55\% clay. Beijing soil is sandy and particle size is smaller whereas Kunming field soil is more clayey and having larger particle size than greenhouse soil. The soil samples were crushed dried and sieved $(1 \mathrm{~mm} \times 1$ $\mathrm{mm}$ mesh). The purpose of using such a fine sieve was to make soil samples more uniform for infiltration of water. After that, the samples were dried in hot air oven at a temperature of $105{ }^{\circ} \mathrm{C}$ for 48 hours (h) then cooled down at room temperature before shifting in the containers (Sharma, Shukla, Bosland, \& Steiner, 2017). The sensor was installed in the container and readings were recorded at the $10 \mathrm{~min}$ interval. The containers during the calibration process were irrigated several times from the top by drip emitters. To calculate the actual value of SWC, soil samples were taken out by using a push probe near the installed sensors ( $\sim 5 \mathrm{~cm}$ away), and holes were packed by the parallel dry soil. The calibration functions were obtained by fitting the estimated and pooled data with linear equations. Their $\mathrm{R}^{2}$ and RMSE values were calculated, respectively.

\subsection{Performance Test Experiments}

The performance of the developed sensor was tested in situ field conditions having different terrain and environmental conditions including Kunming peach field, CAU field, and greenhouse, at different depths. The sensor's stability, ergodicity error rate, transmission accuracy and power consumption events were tested. The soil samples were collected from the respective places and depths. The error rate was calculated by comparing the sensor measured SWC values with that of actual SWC values of oven dried soil samples.

\subsubsection{Multi-depth SWC Curve Experiment}

SWC is a continuous function of soil depth. Therefore, three multi-depth sensors were installed in the CAU field, and vertical distribution of SWC was measured from 12 vertical $0.10,0.15,0.20,0.30,0.35,0.40,0.50,0.55$, $0.60,0.70,0.75$, and $0.80 \mathrm{~m}$ depths all the day long at $1 \mathrm{~h}$ interval. A multi-depth SWC retention curve was 
developed by a linear fit equation to investigate the structural imbalance impact on the continuous estimations of SWC at a specified number of depths on the sensor performance, when converting sensor output voltage to SWC.

\subsubsection{Greenhouse Experiment}

The sensor was installed in a commercial greenhouse from June 2017 to September 2017 and SWC was monitored from 4 different $0.05,0.15,0.25$, and $0.35 \mathrm{~m}$ depths all the day long at a $1 \mathrm{~h}$ interval; the irrigation system was installed at $0.15 \mathrm{~m}$ depth. Three irrigation treatments were applied; irrigation time, irrigated water and the gaps between irrigations were also recorded.

\subsubsection{Kunming Peach Field Experiment}

The sensor was installed in a Kunming peach field for an open field test. The SWC was measured at 0.20, 0.40, 0.60 , and $0.80 \mathrm{~m}$ depths all the day long at the $24 \mathrm{~h}$ interval from March 2017 to June 2017 which includes the spring and early summer seasons.

\subsection{Vertical Interpolation Technique}

Many agricultural processes require the detailed knowledge of the vertical distribution of SWC. The sensor was integrated with an interpolation technique. The SWC time series were measured at $0.20,0.40,0.60$ and $0.80 \mathrm{~m}$ depths and at $0.02 \mathrm{~m}$ increments depth intervals in Kunming peach field on occasional events for the interpolation. The interpolation method uses the detailed time series of SWC at a given depth from one location (used as reference) and rescales it so as to adjust the occasional time series measurements for other location. If at the given depth and at a time " $\mathrm{t}$ " the reference time series SWC value is $\theta_{\mathrm{t}}$ (where " $\mathrm{t}$ " represents the $1 \mathrm{~h}$ interval) and $\grave{\theta}_{\mathrm{t}}$ is the interpolated value for the neighboring location. In order to measure occasional variations in SWC among locations, the measurements between two succeeding time intervals were linearly interpolated. If any pair of values is taken at two consecutive times $\left(t=t_{1}, t=t_{2}\right)$ then,

$$
\begin{aligned}
& \grave{\theta}_{\mathrm{t} 1}=\mathrm{C}_{\mathrm{t} 1} \theta_{\mathrm{t} 1}=\frac{\grave{\mathrm{t}}_{\mathrm{t} 1}}{\theta_{\mathrm{t} 1}} \theta_{\mathrm{t} 1} \\
& \grave{\theta}_{\mathrm{t} 2}=\mathrm{C}_{\mathrm{t} 2} \theta_{\mathrm{t} 2}=\frac{\grave{\theta}_{\mathrm{t} 2}}{\theta_{\mathrm{t} 2}} \theta_{\mathrm{t} 2}
\end{aligned}
$$

Where $\mathrm{C}_{\mathrm{t} 1}$ and $\mathrm{C}_{\mathrm{t} 2}$ are the ratios of SWC at a given depths for each time. The coefficients were supposed to differ linearly, which produces Equation 9 for the interpolation of SWC at any time $\times$ between $\left(t=t_{1}, t=t_{2}\right)$.

$$
\theta_{\mathrm{x}}=\theta_{\mathrm{x}}\left[\mathrm{C}_{\mathrm{t} 1}+\frac{\mathrm{C}_{\mathrm{t} 2}-\mathrm{C}_{\mathrm{ct} 1}}{\mathrm{t}_{2}-\mathrm{t}_{1}}(\mathrm{x}-\mathrm{t})\right], \mathrm{x} \in\left[\mathrm{t}_{1}, \mathrm{t}_{2}\right]
$$

The sensor measured SWC data from 4 depths were compared with the linear interpolated SWC values at same depths within the same time interval. The corresponding depths measured SWC data on different time interval showed similar patterns, then for each $0.02 \mathrm{~m}$ depth interval "i", the ratio $\left(\gamma_{\mathrm{i}}\right)$ between the actual $\left(\theta_{\mathrm{t}}\right)$ and the interpolated $\left(\grave{\theta}_{\mathrm{t}}\right)$ SWC was remarkably close. Therefore, the mean value of each depth $\left(\bar{\gamma}_{\mathrm{i}}\right)$ used as a scale to the interpolated data by:

\section{Results and Discussion}

$$
\theta_{\mathrm{t}}=\bar{\gamma}_{\mathrm{i}} \grave{\theta}_{\mathrm{t}}
$$

\subsection{Sensor Calibration}

Three calibration experiments showed significant results and determined that the sensor could perform equally better in different moist conditions. The measured voltage and the relevant SWC were fitted by a linear equation. Figure 4 shows the linear calibration curves. The corresponding equations are shown in Table 1.

Table 1. Linear fit equations

\begin{tabular}{llll}
\hline Linear fit Plot & Equation & $\mathbf{R}^{2}$ & RMSE \\
\hline Kunming field SWC & $\mathrm{y}=-3.99637+26.49807 \mathrm{x}$ & 0.984 & 3.002 \\
CAU field SWC & $\mathrm{y}=-1.88846+23.81843 \mathrm{x}$ & 0.957 & 4.456 \\
Greenhouse SWC & $\mathrm{y}=0.58451+24.63038 \mathrm{x}$ & 0.961 & 3.030 \\
Pooled data & $\mathrm{y}=-2.93737+26.08346 \mathrm{x}$ & 0.993 & 1.565 \\
\hline
\end{tabular}

Note. Null hypothesis has been tested at a 5\% significance level. 
Where $\mathrm{x}$ was sensor output voltage $(\mathrm{mV})$ and $\mathrm{y}$ was the $\mathrm{SWC}$. The linear fit $\mathrm{R}^{2}$ values ranged from 0.957 to 0.993 , and RMSE was ranging from 1.565 to 4.456 .
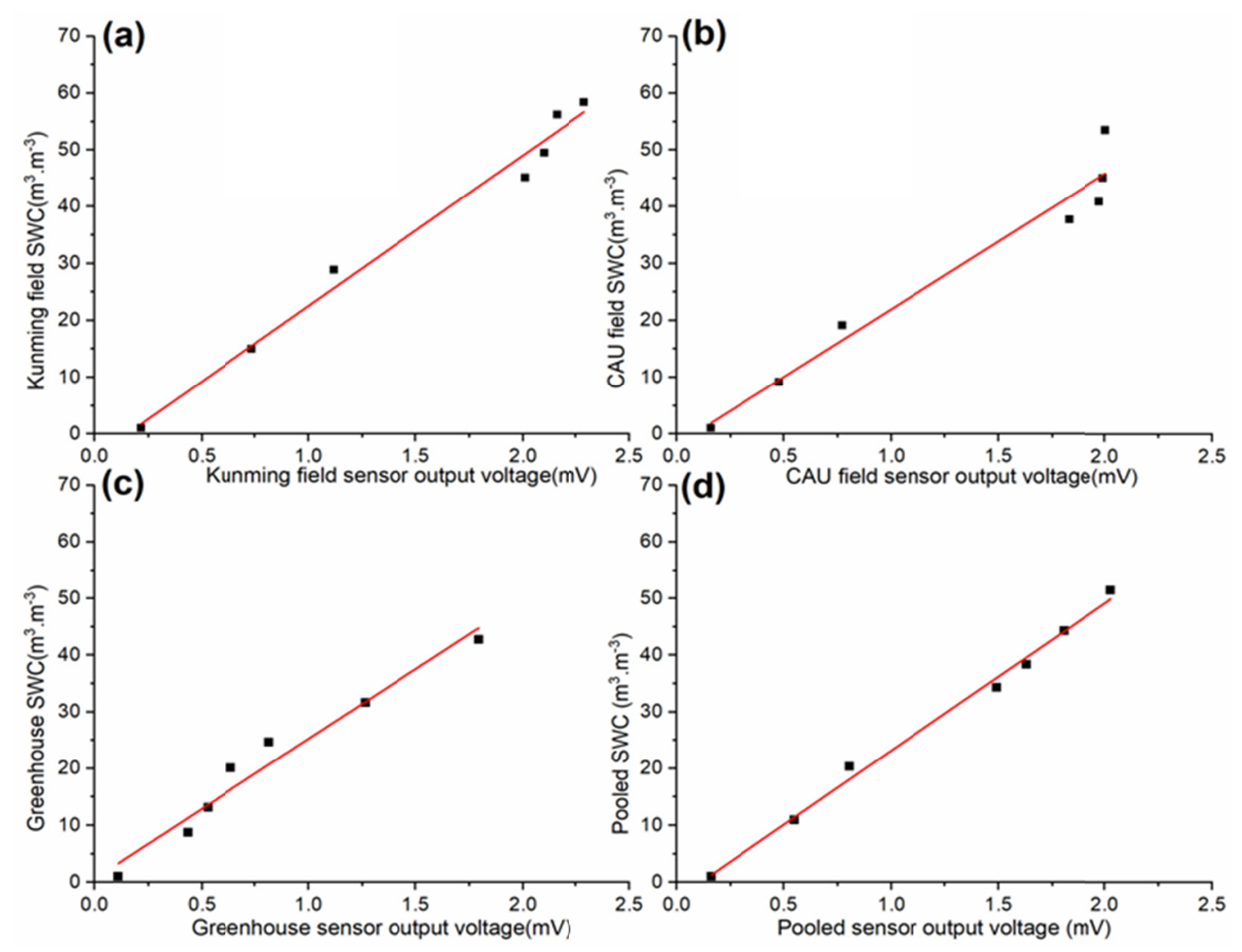

Figure 4. Linear fit curves for SWC calibration showing the relationship with sensor output Voltage

\subsection{Performance Tests}

The performance of the sensor was tested on three in situ measurement ranges having a different terrain and environmental conditions. The results demonstrated that the sensor's stability, ergodicity error rate, transmission accuracy and power consumption was remarkably well in all experiments.

\subsubsection{Multi-depth SWC Curve Measurements}

\section{(1) CAU Field Multi-depth SWC}

The measured SWC from 12 vertical depths was fitted by the linear order equation and results were found significant at a $5 \%$ significance level. Figure 5 shows a multi-depth SWC curve. Equation 11 is the corresponding equation. The R2 was 0.769 , and RMSE was 3.008 , respectively.

$$
\mathrm{y}=10.5739+22.02097 \mathrm{x}
$$

Where $\mathrm{x}$ is vertical soil depth in meters and $\mathrm{y}$ is $\operatorname{SWC}\left(\mathrm{m}^{3} \mathrm{~m}^{-3}\right)$ value. 


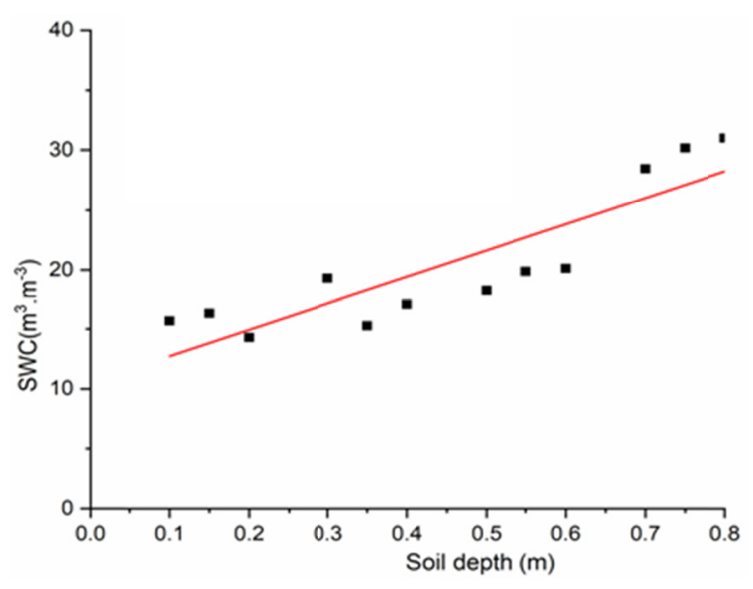

Figure 5. CAU field multi-depth SWC curve

Figure 5 presents the site-specific SWC retention curve. The curve was developed based on the actual measured SWC data rather than projected values. Various studies have been conducted to plot SWC curves based on the projected soil textural properties. The soil is an asymmetrical porous medium, and the variability in mineralogy and terrain properties at different depths might impact continuous monitoring of SWC. The interannual variations in other soil structure and natural soil environment can also impact the SWC curve (Rawls, Gish, \& Brakensiek, 1991; Saxton \& Rawls, 2006). A multi-depth and site-specific SWC retention curve were developed to derive precise site-specific calibration curve, and to improve the sensor performance because the sensor was installed in various fields at different depths. The developed multi-depth SWC curve for a soil in a region can also help agricultural producers when estimating in situ SWC in the vertical profile.

(2) Greenhouse Experiment Results

The greenhouse environment is managed differently and microclimate inside is different than open fields. The monitored SWC from 4 different soil depths along with irrigation treatments is shown in Figure 6.

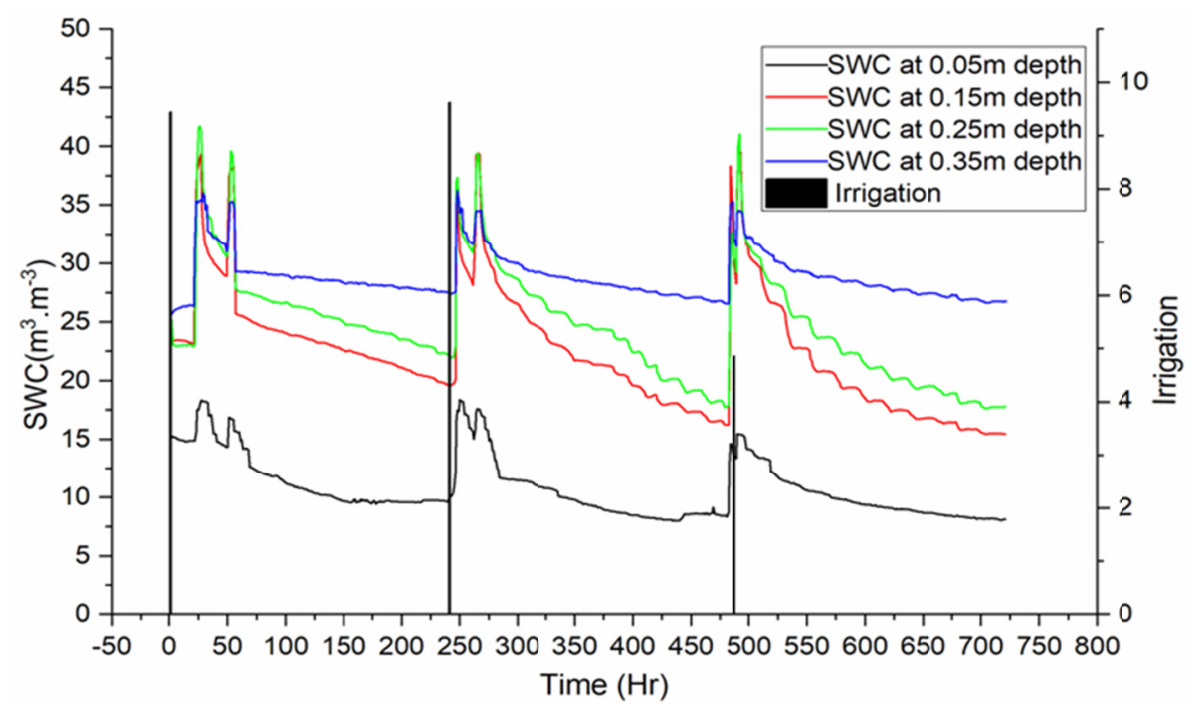

Figure 6. Greenhouse measured SWC with irrigation at different soil depths

The greenhouse experiment shows that the sensor captured the major SWC patterns at all depths, except for the few data points during and sudden after the irrigation events. The SWC at $0.15 \mathrm{~m}$ depth steeped than $0.05 \mathrm{~m}$ depth. The variations in measurements can be attributed to irrigation amount, infiltration rate, gaps between two irrigations and also the distance from the irrigation source (installed at $0.15 \mathrm{~m}$ depth) (Mwale, Azam-Ali, \& Sparkes, 2005). The capacitance probes are inclined to high magnitude of SWC surrounding the probe. The EM 
field trails to conductive areas and principally radiates into wetter zones. Therefore, any change in the SWC surrounding the probe will generate different trends of the EM field which will impact sensor measurements (Evett, Schwartz, Casanova, \& Heng, 2012).

\section{(3) Kunming Peach Field Experiment Results}

The estimated SWC from 4 different soil depths is shown in Figure 7. The sensor performed markedly well during the study period.

Figure 7 illustrates the Kunming field SWC estimations. The sensor showed dynamic variations in results at $0.20 \mathrm{~m}$ depth because the near-surface SWCs varies significantly and could easily be influenced by the hydrological conditions than deeper SWCs (Jiang, Liu, \& Zhang, 2017; Plauborg, Iversen, \& Lærke, 2005). However, at $0.40 \mathrm{~m}$ depth sensor performance was consistent whereas the sensor measurements at $0.60-0.80 \mathrm{~m}$ depths were more stable than upper depths.

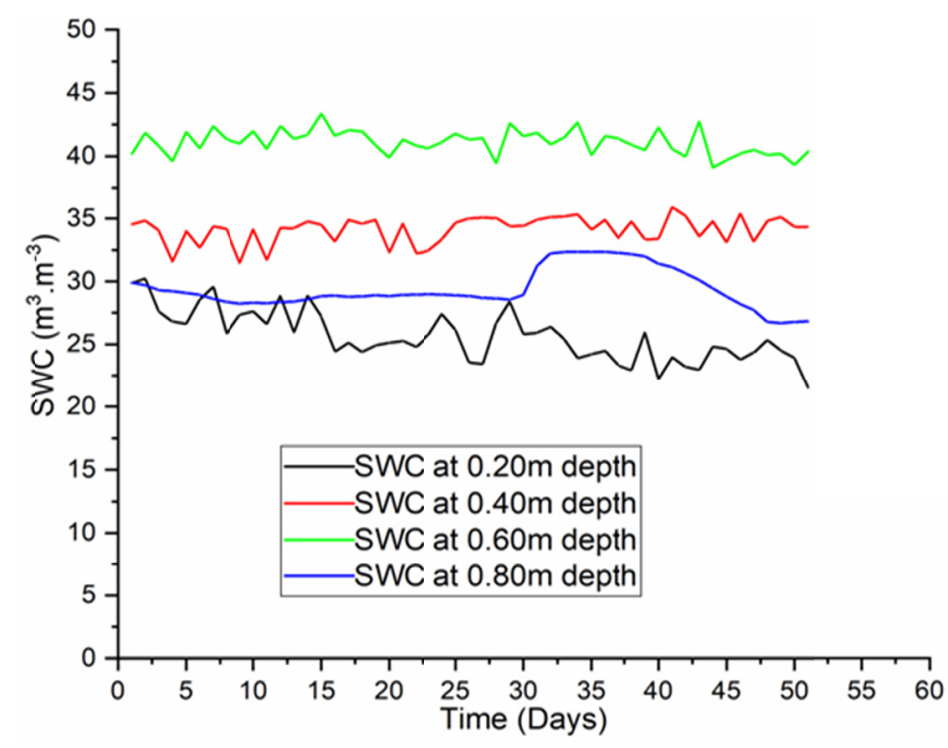

Figure 7. Kunming field measured SWC at different depths

The small variations in the sensor results could be subjected to in situ field conditions, and also to the complex movement of the SWC in the vertical profile (Fernández-Gálvez et al., 2006; Gao, Lv, Wang, Tahir, \& Peng, 2015; Wilson et al., 2003).

\subsubsection{Power Consumption}

Hardware and software were designed and tested to meet low power consumption, moreover, to ensure that the sensor can function constantly at least for 4 months. The probe was assessed in different working modes including; active, passive, and data communication mode. The power consumption rate for each mode was calculated. The average power consumption of the sensor was $16.1 \mu \mathrm{A}$ in sleep mode, $14.8 \mathrm{~mA}$ during data sensing, $34.6 \mathrm{~mA}$ when sending data, and $14.9 \mathrm{~mA}$ while receiving data.

\subsection{Vertical Interpolation of SWC Data}

The direct comparison between the actual and linear interpolated SWC is shown in Figure 8. For each depth, there was a remarkable correlation between the measured and interpolated SWC values. The average value of each depth, therefore, provided a scaling factor to change the SWC measurements at any depth in the measurement range. The interpolation techniques can be used to derive the SWC profile at $0.02 \mathrm{~m}$ depth resolution from the SWC data at relative depths. The near-surface SWC values could be used to estimate the SWC at deeper depths because these soil depths are also subjected to the same climate and field conditions (Brocca, Melone, Moramarco, \& Morbidelli, 2009; Kornelsen \& Coulibaly, 2012). 


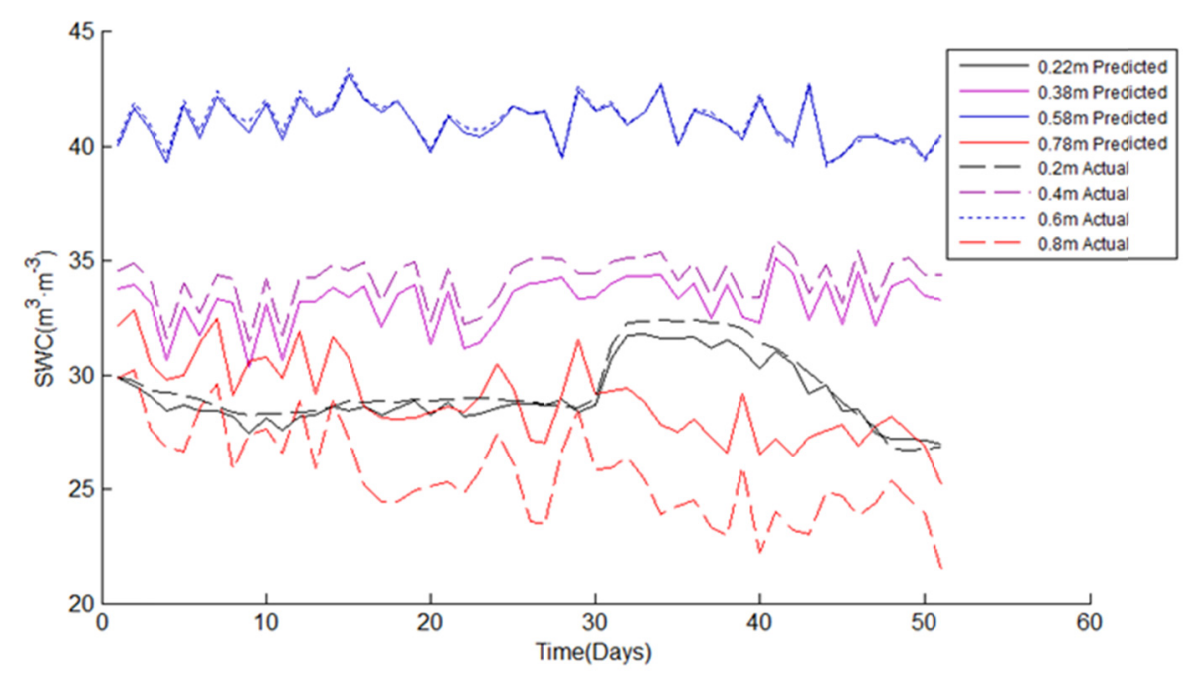

Figure 8. Direct comparison between measured and interpolated SWC, Kunming field

There were some variations in the SWC measurements because the distribution of SWC varies with space, time and depth and the upper depths SWC could easily be driven by environmental conditions than deeper depths.

\subsection{System Error Analysis}

The system error rate was calculated by comparing the sensor measured SWC values with that of actual SWC values of oven dried soil samples. In any case, the error rate was less than $5 \%$ in repeating experiments, except the irrigation. Whereas Figure 9 shows the error rate of actual and interpolated SWC values. The overall error rate was less than $5 \%$, except for the upper depths.
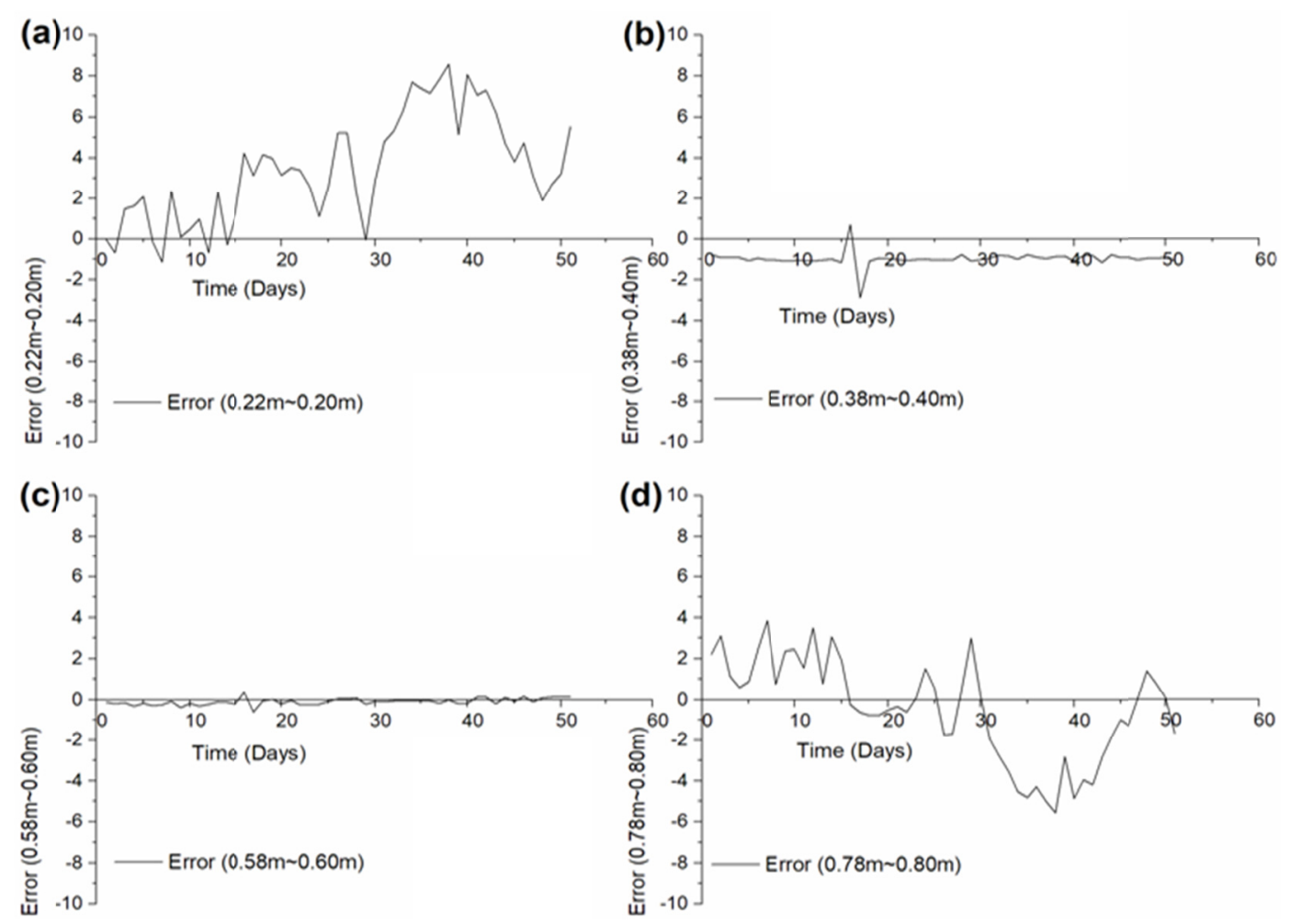

Figure 9. Error graphs of measured and interpolated SWC 
Our research reported that the most of the results were in close agreement with reference findings, and revealed the potential of the developed sensor for the SWC measurements. The sensor responded markedly well for all measured soil depths, especially at the $0.60 \sim 0.80 \mathrm{~m}$ depths. Whereas at the few points the variations in sensor measurements were subjected to irrigation events, clay and sandy contents in in situ soil structure. The temporal variability of SWC (dielectric constant steeps with water contents) could be influenced by the soil hydraulic and matric potential, infiltration process, subsequently will influence the sensor measurements (Evett et al., 2012; Evett, Tolk, \& Howell, 2006; Rudnick, Djaman, \& Irmak, 2015).

The results determined that the sensor captured the major magnitude of SWC in the vertical profile in different environmental and terrain conditions. It can be used to develop the smart irrigation strategies in the research area following the site-specific calibrations for various soil horizons. The developed sensor will be more advantageous if similar soil moisture management strategies prevail across the year then it becomes possible to plot a field calibration curve to resolve the aforementioned issues associated with sensing technology. The un-calibrated sensor can be used for scheduling the irrigation management but it will limit the research work (Irmak \& Irmak, 2005).

\section{Conclusions}

This study presents a development of a multi-depth wireless SWC sensor based on the dielectric theory. A particular estimation method, as well as the hardware, has been introduced. The performance of the developed sensor was thoroughly tested under various in situ environmental conditions. The sensor was calibrated by using soil samples collected from different sites. The linear order SWC prediction models were established. A multi-depth SWC curve was established to examine the impact of continuous estimations of SWC at a specified number of depths on the sensor performance. An interpolation technique was used to estimate the SWC in the vertical profile. The interpolated SWC patterns were also correlated with the sensor measured SWC values, but at some points, measurements showed slight variations in individual results. In situ experiments indicated that estimation error was less than 5\%, except irrigation events. It is recommended that the sensor should be used after the infiltration of irrigated water for better results. The sensor can work and transfer consistently for at least 4 months with $2100 \mathrm{mAh} / 3.6 \mathrm{~V}$ battery. Hence, the newly developed multi-depth sensor is advantageous for estimating and managing SWC under actual environmental conditions.

\section{Acknowledgements}

The authors would like to thank their colleagues for their support for this work. The detailed comments from the anonymous reviewers were gratefully acknowledged. This work was supported by China Postdoctoral Science Foundation (2018M630222); Open Project Program of National Engineering Laboratory for Agri-product Quality Traceability, Beijing Technology and Business University (BTBU) and Project of Scientific Operating Expenses from Ministry of Education of China (2017PT19), and National Natural Science Foundation (31471409).

\section{References}

Baldwin, D., Manfreda, S., Keller, K., \& Smithwick, E. A. H. (2017). Predicting root zone soil moisture with soil properties and satellite near-surface moisture data across the conterminous United States. Journal of Hydrology, 546, 393-404. https://doi.org/10.1016/j.jhydrol.2017.01.020

Brocca, L., Melone, F., Moramarco, T., \& Morbidelli, R. (2009). Soil moisture temporal stability over experimental areas in Central Italy. Geoderma, 148(3-4), 364-374. doi: https://doi.org/10.1016/j.geoderma. 2008.11.004

Chow, L., Xing, Z., Rees, H. W., Meng, F., Monteith, J., \& Stevens, L. (2009). Field performance of nine soil water content sensors on a sandy loam soil in new brunswick, maritime region, Canada. Sensors (Basel), 9(11), 9398-9413. https://doi.org/10.3390/s91109398

Dean, T. (1994). The IH capacitance probe for measurement of soil water content. Institute of Hydrology.

Dean, T., Bell, J., \& Baty, A. (1987). Soil moisture measurement by an improved capacitance technique, Part I. Sensor design and performance. Journal of Hydrology, 93(1-2), 67-78.

Entekhabi, D., Njoku, E. G., O’Neill, P. E., Kellogg, K. H., Crow, W. T., Edelstein, W. N., ... Johnson, J. (2010). The soil moisture active passive (SMAP) mission. Proceedings of the IEEE, 98(5), 704-716.

Evett, S. R., Schwartz, R. C., Casanova, J. J., \& Heng, L. K. (2012). Soil water sensing for water balance, ET and WUE. Agricultural Water Management, 104, 1-9. 
Evett, S. R., Tolk, J. A., \& Howell, T. A. (2006). Soil profile water content determination. Vadose Zone Journal, 5(3), 894-907.

Evett, S., Heng, L., Moutonnet, P., \& Nguyen, M. (2008). Field estimation of soil water content: A practical guide to methods, instrumentation, and sensor technology. IAEA: Vienna.

Fernández-Gálvez, J., Simmonds, L. P., \& Barahona, E. (2006). Estimating detailed soil water profile records from point measurements. European Journal of Soil Science, 57(5), 708-718. https://doi.org/10.1111/ j.1365-2389.2005.00761.x

Gao, L., Lv, Y., Wang, D., Tahir, M., \& Peng, X. (2015). Can shallow-layer measurements at a single location be used to predict deep soil water storage at the slope scale? Journal of Hydrology, 531, Part 3, 534-542. https://doi.org/10.1016/j.jhydrol.2015.11.002

Greco, R., \& Guida, A. (2008). Field measurements of topsoil moisture profiles by vertical TDR probes. Journal of Hydrology, 348(3-4), 442-451. https://doi.org/10.1016/j.jhydrol.2007.10.013

Hignett, C., \& Evett, S. (2008). Direct and surrogate measures of soil water content.

Holmes, T. R., Crow, W. T., Jackson, T. J., De Jeu, R., Reichle, R., \& Cosh, M. (2012). Assessment of soil moisture retrieval with numerical weather prediction model temperatures. Paper presented at the International Association of Hydrological Science.

İmamoğlu, M. Z., \& Sertel, E. (2016). Analysis of Different Interpolation Methods for Soil Moisture Mapping Using Field Measurements and Remotely Sensed Data.

Irmak, S., \& Irmak, A. (2005). Performance of Frequency-Domain Reflectometer, Capacitance, and Psuedo-Transit Time-Based Soil Water Content Probes in Four Coarse-Textured Soils. Applied Engineering in Agriculture, 21(6), 999-1008.

Jiang, X. J., Liu, S., \& Zhang, H. (2017). Effects of different management practices on vertical soil water flow patterns in the Loess Plateau. Soil and Tillage Research, 166, 33-42. https://doi.org/10.1016/j.still.2016. 10.001

Kargas, G., \& Kerkides, P. (2009). Performance of the theta probe ML2 in the presence of nonuniform soil water profiles. Soil and Tillage Research, 103(2), 425-432.

Kelleners, T., Soppe, R., Robinson, D., Schaap, M., Ayars, J., \& Skaggs, T. (2004). Calibration of capacitance probe sensors using electric circuit theory. Soil Science Society of America Journal, 68(2), 430-439.

Kornelsen, K., \& Coulibaly, P. (2012). Comparison of interpolation, statistical, and data-driven methods for imputation of missing values in a distributed soil moisture dataset. Journal of Hydrologic Engineering, 19(1), 26-43.

Kumar, D., Jonnalagadda, S., Jain, P., Gawande, N. A., Townsend, T. G., \& Reinhart, D. R. (2009). Field evaluation of resistivity sensors for in situ moisture measurement in a bioreactor landfill. Waste Manag, 29(5), 1547-1557. https://doi.org/10.1016/j.wasman.2008.10.020

Leib, B. G., Jabro, J. D., \& Matthews, G. R. (2003). Field evaluation and performance comparison of soil moisture sensors. Soil Science, 168(6), 396-408.

Li, B., Toll, D., Zhan, X., \& Cosgrove, B. (2012). Improving estimated soil moisture fields through assimilation of AMSR-E soil moisture retrievals with an ensemble Kalman filter and a mass conservation constraint. Hydrology and Earth System Sciences, 16(1), 105-119.

Li, X., Shao, M. A., Jia, X., \& Wei, X. (2016). Profile distribution of soil-water content and its temporal stability along a 1340-m long transect on the Loess Plateau, China. CATENA, 137, 77-86. https://doi.org/10.1016/ j.catena.2015.09.005

Ling, P. (2004). A review of soil moisture sensors. Assn. Flor. Prof. Bull, 886, 22-23.

Luhr, K., \& Kleisinger, S. (1998). A test procedure for soil moisture sensors. Gartenbauwissenschaft (Germany).

Mittelbach, H., Lehner, I., \& Seneviratne, S. I. (2012). Comparison of four soil moisture sensor types under field conditions in Switzerland. Journal of Hydrology, 430-431, 39-49. https://doi.org/10.1016/j.jhydrol.2012. 01.041

Morbidelli, R., Corradini, C., Saltalippi, C., \& Brocca, L. (2012). Initial soil water content as input to field-scale infiltration and surface runoff models. Water Resources Management, 26(7), 1793-1807. 
Mwale, S., Azam-Ali, S., \& Sparkes, D. (2005). Can the PR1 capacitance probe replace the neutron probe for routine soil-water measurement? Soil Use and Management, 21(3), 340-347.

Ojha, R., Morbidelli, R., Saltalippi, C., Flammini, A., \& Govindaraju, R. S. (2014). Scaling of surface soil moisture over heterogeneous fields subjected to a single rainfall event. Journal of Hydrology, 516, 21-36. https://doi.org/10.1016/j.jhydrol.2014.01.057

Pal, M., Maity, R., \& Dey, S. (2016). Statistical Modelling of Vertical Soil Moisture Profile: Coupling of Memory and Forcing. Water Resources Management, 30(6), 1973-1986.

Parsons, L. R., \& Bandaranayake, W. M. (2009). Performance of a New Capacitance Soil Moisture Probe in a Sandy Soil. Soil Science Society of America Journal, 73(4), 1378. https://doi.org/10.2136/sssaj2008.0264

Plauborg, F., Iversen, B. V., \& Lærke, P. E. (2005). In situ comparison of three dielectric soil moisture sensors in drip irrigated sandy soils. Vadose Zone Journal, 4(4), 1037-1047.

Rawls, W., Gish, T., \& Brakensiek, D. (1991). Estimating soil water retention from soil physical properties and characteristics. Adv. Soil Sci., 16, 213-234.

Romano, N. (2014). Soil moisture at local scale: Measurements and simulations. Journal of Hydrology, 516, 6-20. https://doi.org/10.1016/j.jhydrol.2014.01.026

Rudnick, D. R., Djaman, K., \& Irmak, S. (2015). Performance analysis of capacitance and electrical resistance-type soil moisture sensors in a silt loam soil. Transactions of the ASABE, 58(3), 649-665.

Saxton, K. E., \& Rawls, W. J. (2006). Soil water characteristic estimates by texture and organic matter for hydrologic solutions. Soil Science Society of America Journal, 70(5), 1569-1578.

Sharma, H., Shukla, M. K., Bosland, P. W., \& Steiner, R. (2017). Soil moisture sensor calibration, actual evapotranspiration, and crop coefficients for drip irrigated greenhouse chile peppers. Agricultural Water Management, 179, 81-91. https://doi.org/10.1016/j.agwat.2016.07.001

Stacheder, M., Koeniger, F., \& Schuhmann, R. (2009). New dielectric sensors and sensing techniques for soil and snow moisture measurements. Sensors (Basel), 9(4), 2951-2967.

Stangl, R., Buchan, G. D., \& Loiskandl, W. (2009). Field use and calibration of a TDR-based probe for monitoring water content in a high-clay landslide soil in Austria. Geoderma, 150(1-2), 23-31. https://doi.org/10.1016/j.geoderma.2009.01.002

Stewart, J. (1996). Scaling up in hydrology using remote sensing. John Wiley and Sons.

Topp, G. C. (2003). State of the art of measuring soil water content. Hydrological Processes, 17(14), 2993-2996.

Topp, G. C., Davis, J., \& Annan, A. P. (1980). Electromagnetic determination of soil water content: Measurements in coaxial transmission lines. Water Resources Research, 16(3), 574-582.

Walker, J. P., Willgoose, G. R., \& Kalma, J. D. (2004). In situ measurement of soil moisture: a comparison of techniques. Journal of Hydrology, 293(1-4), 85-99. https://doi.org/10.1016/j.jhydrol.2004.01.008

Wang, Y., Hu, W., Zhu, Y., Shao, M. A., Xiao, S., \& Zhang, C. (2015). Vertical distribution and temporal stability of soil water in 21-m profiles under different land uses on the Loess Plateau in China. Journal of Hydrology, 527, 543-554. https://doi.org/10.1016/j.jhydrol.2015.05.010

Western, A. W., Grayson, R. B., \& Blöschl, G. (2002). Scaling of Soil Moisture: A Hydrologic Perspective. Annual Review of Earth and Planetary Sciences, 30(1), 149-180. https://doi.org/10.1146/annurev. earth.30.091201.140434

Wilson, D. J., Western, A. W., Grayson, R. B., Berg, A. A., Lear, M. S., Rodell, M., .. McMahon, T. A. (2003). Spatial distribution of soil moisture over 6 and $30 \mathrm{~cm}$ depth, Mahurangi river catchment, New Zealand. Journal of Hydrology, 276(1-4), 254-274. https://doi.org/10.1016/S0022-1694(03)00060-X

\section{Copyrights}

Copyright for this article is retained by the author(s), with first publication rights granted to the journal.

This is an open-access article distributed under the terms and conditions of the Creative Commons Attribution license (http://creativecommons.org/licenses/by/4.0/). 